\title{
Estimating Maintenance Costs of a Wind Turbine Pitch Control System
}

\author{
E. Nunes \& J. Telhada \\ Centro Algoritmi, University of Minho, Braga, Portugal
}

M. Carvalho

Polytechnic Institute of Cávado and Ave, Barcelos, Portugal

\begin{abstract}
Wind turbines are nowadays the principal source of wind energy production. However, the technical information publicly known about these machines is still very scarce. Indeed, information related to failure modes, unavailability and maintenance costs of these systems remains confidential and only is held by manufacturers. To be able to optimize the efficiency, to guarantee the security and to negotiate better warranty and maintenance contracts, it is necessary to know more information about the operation and maintenance and replacement costs of subsystems of a wind turbine. To this end, this paper presents a short literature review of what has been published so far about this issue, and, based on two years of operation, analyses an active power control system of 21 identical wind turbines, installed in a wind farm in Portugal. The emphasis of this study is on the operation, availability and maintenance, and replacement costs of the active pitch control device, which automatically manages the position and operation of blades according to wind direction and speed, thus maximizing the electrical power gathered from the natural forces. Moreover, the paper provides an estimation for the total maintenance cost of this device, one of the most important components of the wind turbine, thus allowing wind farm companies to carry out financial and economic analysis of maintenance contracts that probably will be the rationale for better contract negotiations with manufactures. The result and the analyses that have been reported may also contribute for further studies on the reliability and maintenance policies of wind turbines.
\end{abstract}

\section{INTRODUCTION}

Wind power technology is one of the major growing areas in the energy sector. In a time period of a few years wind power has gone from a minor energy source to a large-scale industry. However, the adoption of wind power has not been an ease process. A lot of teething troubles have been causing problems to the relatively new technology. Operating wind power systems have proven to be difficult, with wind turbines (WTs) shutting down frequently due to various types of failures. In addition, a general trend has been towards the erection of larger wind turbines at remote sites. Hence, proper and wellplanned service and maintenance strategies are very important to ensure an efficient energy production and required to effectively reduce the costs associated with WT support.

For a regular and economical wind power generation, it is necessary to maintain each wind turbine handling unit, taking in account the environment conditions, operating conditions and others. According to Kumar \& Pandey (1993), the failure rate of each subsystem in a particular system depends on the operating conditions and repair policies used.
Maintenance can be performed in order to prevent failures (preventive maintenance, e.g. at scheduled intervals) or to repair a failure (corrective maintenance). Maintenance management approaches imply to find a sound balance between costs and benefits of performing maintenance. Experience and studies show that there is a large potential to reduce overall costs in the maintenance of wind turbines (Bertling et al. 2006).

According to Morthorst (2003), Operation and Maintenance costs (O\&M), (which include a limited number of cost components such as insurance, regular maintenance, repairs, spare parts and administration) constitute a sizeable share of the total annual costs of a WT. For a new machine, O\&M costs might easily have an average share over the lifetime of the turbine of approximately $20 \%$ to $25 \%$ of the total cost per $\mathrm{kWh}$ produced.

A primordial part of a wind turbine is the active power control system. It assumes a primordial importance because: i) it is crucial in the optimization of the turbine efficiency; and ii) it is very important with regard to the safety of the turbine by protecting its integrity in bad weather conditions (Naranjo et al. 2011). The problem is that this system reveals fre- 
quent failures and large residence time in failure, when compared to other systems of the machine (Julia. \& Lina 2007). Consequently, to guarantee a normal operation, it needs maintenance actions, which are usually provided by the manufacturer, exclusively (Teresa 2007). Moreover, the real costs of these maintenance actions are unknown by the company that manage the wind farm. This situation does not facilitate, for example, the work of company managers who search for better warranty and maintenance contracts.

In an attempt to shed some light on this problem, the present work addresses, in particular, the pitch control system.. This study is based on an analysis of data collected from 21 wind turbines installed in a wind farm in Portugal, during two years. The data collected basically consisted on the register of the exact time of occurrence of a particular state and the wind speed at the time of this occurrence in each turbine, allowing to performing some statistical analyses (Qiu et al. 2012). On the other hand, it was possible to gather complementary and additional information from semi-structured interviews to experts who thus shared their knowledge and experience on working with these systems.

These data were provided confidentially by the company that manages the wind farm. Thus, the name of the company and the wind turbine brand are not revealed.

The wind farm that provided the information holds more than one type of turbines. The selection of the type of wind turbine to analyse was based on two main criteria, namely:

i) being the most recent ones, and

ii) being in a greater number than the other types.

The turbine under analysis has three rotor blades and an active power control. The nominal power of the system is $2 \mathrm{MW}$.

The main objective of this paper consists on reporting the gathering process of information about wind turbine functioning and its failures and costs, and conducting some reliability analyses, providing, at the end, an estimate of the associated maintenance costs of the active power control system (pitch system). The knowledge of this estimation may be important to the company by allowing their managers to make better decisions relatively to maintenance of wind turbines.

\subsection{Wind energy in Portugal}

Wind energy is harnessing the kinetic energy supplied by the wind to produce mechanical energy (rotation of blades), which can then be transformed into electrical energy by a generator.

The wind has been used for thousands of years to meet the energy needs of human activity, e.g. for powering transportation (sailing boats), pumping water and permit the operation of industrial activities, as was the case of windmills, still visible at the top of many Portuguese hills, for example. As is the case of most renewable energy sources (except geothermal), wind energy is a form of solar energy that comes from the heating of the atmosphere by the sun, which sets in motion the air masses. The earth's rotation, shape and coverage of the land surface and the water levels influence the speed, direction and wind variability in a given place.

Wind energy is increasingly used to produce electricity. It is often decentralized to local use, such as in isolated places (e.g. agricultural farms), but it is also increasingly associated to medium and large electric production in wind farms consisting of several wind turbines connected to the general electric network system, in particular in Europe and other occidental countries. Figure 1 shows the wind generating capacity observed in Portugal and other European countries by December 2010 (INEGI 2010).

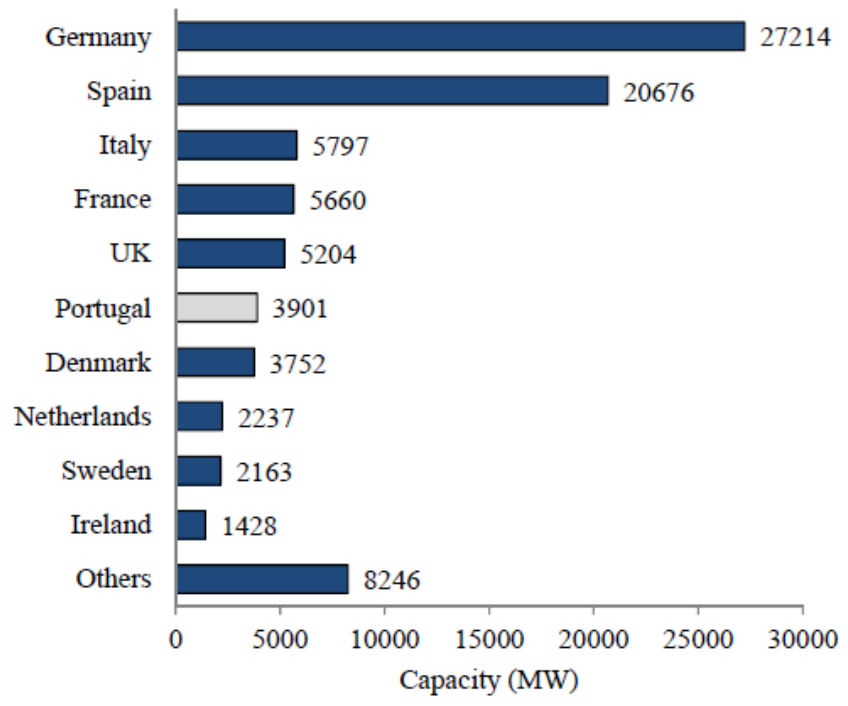

Figure 1. Generating capacity of wind power base - Europe, December 2010 ( INEGI, 2010)

Table 1 shows the capacity of wind generation and the number of wind turbines in Portugal in 2010.

Table 1. Generating capacity and number of wind turbines, Portugal, December 2010 (INEGI 2010)

\begin{tabular}{lccccccc}
\hline Wind farms & \multicolumn{2}{c}{ Full operational } & \multicolumn{2}{c}{ In Construction } & \multicolumn{2}{c}{ Total } \\
in Portugal & MW & Turbines & MW & Turbines & MW & Turbines \\
\hline Mainland & 3852.5 & 2027 & 435.3 & 216 & 4287.8 & 2243 \\
Madeira & 37.4 & 58 & 0.0 & 0 & 37.4 & 58 \\
Azores & 11.6 & 33 & 9.0 & 10 & 20.6 & 43 \\
Total & 3901.4 & 2118 & 444.3 & 226 & 4345.7 & 2344 \\
\hline
\end{tabular}

\subsection{Paper organization}

This chapter is an extended version of the paper presented at the World congress on Engineering 2013 (Carvalho et al. 2013). 
The paper is structured as follows: Section 2 describes the normal operation of the wind turbine type under analysis. Specifically, it presents the maintenance policy of the wind farm, the main states detected on the wind turbine and a detailed description of the pitch system. Section 3 analyses and estimates the maintenance costs for an active power control system, namely the unavailability cost, preventive and corrective maintenance costs and replacement costs. It finishes with an estimate of the total cost of maintenance of an active power control system. Finally, Section 4 synthetizes the main conclusions of this work.

\section{DESCRIPTION OF A WIND TURBINE}

\subsection{Introduction}

All wind turbines, regardless of their size, consist on the following components: the rotor (the part that runs on wind and where they attach the blades), the electrical generator, a speed control system and the tower. Wind turbines also have a security system that, in case of failure of any of their components, prevents the movement of the blades. Turbines usually uses an horizontal axis, essentially consisting of a tower of 50 to 120 meters height, on the top of which is a rotor with (typically) three blades (each paddle has a length of 25 to 45 meters), and the nacelle that houses the generator itself, as well as the control systems of the machine.

The wind sets into motion the vanes that perform 10 to 25 revolutions per minute, approximately. The generator contained in the nacelle turns the mechanical energy of this rotational motion into electrical energy. An automated real-time control allows the nacelle to rotate, in order to ensure that it always face the wind, and the blades to permanently adjust their inclination to always maximize the energy captured (active power control). Figure 2 shows the major parts of the wind turbine.

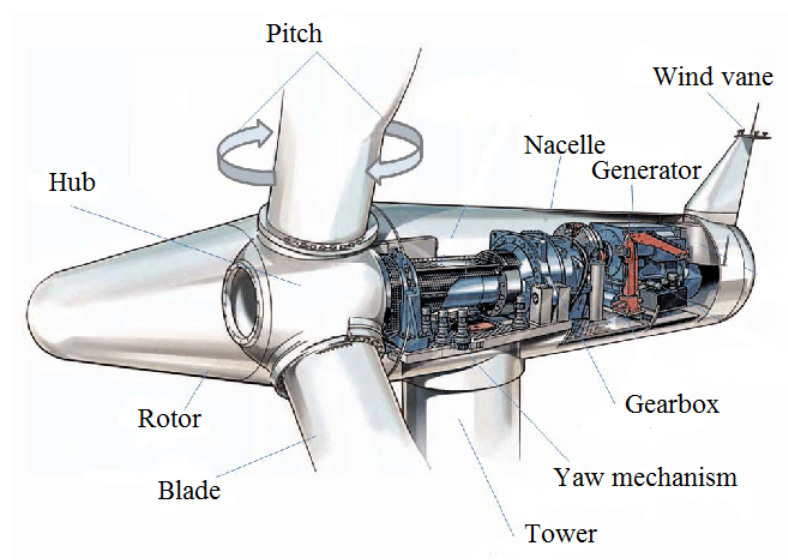

Figure 2. Wind turbine parts (modified Siemens Press Picture, Siemens AG, 2007)
Nowadays, the most commonly wind turbines installed in wind farms have a power of 2 to $3 \mathrm{MW}$ (megawatts), which means that a turbine of this type can supply the electricity needs of 2 to 3 thousands homes.

In general, any energy produced by the turbine increases with the wind speed. However, this happens only to a critical limit. In the case of strong winds, the turbine blades are guided by the pitch control to be in line (parallel) position with the wind in order to protect themselves. The windiest sites are generally situated along the sea coast or on mountain tops. In a particular place, the speed normally increases with the altitude as the wind suffers less friction with the surface of earth. For this reason, the turbines are typically mounted on high towers.

\subsection{Wind turbine service and maintenance policy}

Determining a proper maintenance policy is an important task in the maintenance planning. Generally, maintenance policies are classified into two types: corrective maintenance and preventive maintenance. In repairable systems, both of these types of maintenance play a key role in the system behaviour and have significant effects in terms of reliability, availability and operating costs. In fact, the cost is always a key factor in planning preventive maintenance, since the reliability and the risk are often expressed in terms of cost. Accordingly, the type and level of service that are used in practice depend on the type of applications, system costs, but also reliability and safety requirements (Pham \& Wang, 1996).

In recent decades, the problems of maintenance and replacement of systems subject to deterioration have been studied extensively in the literature. Garg \& Deshmukh (2006) present a review of the main works developed in recent years.

In general, WT preventive maintenance is performed once or twice per year, depending on what requirements the WT manufacturer has set up in the maintenance contract. During the preventive maintenance, some parts are controlled and some are exchanged. Oils and lubricating greases are changed or refilled for several different parts. Normally it takes a couple of days for two persons to perform a preventive maintenance action. This type of service actions is often planned to be performed during the summers when wind speeds are low (Walford 2006). The corrective maintenance is performed when a fault signal is sent from the WT to the control centre. The signal contains one or several codes explaining which type(s) of fault has occurred (Manwell et al. 2002).

Usually, the acquisition of a WT includes a maintenance (or service) contract. A normal maintenance contract states that the manufacturer has full responsibility for the WT function over the contrac- 
tual time. This means that the WT manufacturer handles all maintenance and provides personnel and spare part storage for the wind farm (Walford 2006).

For the wind farm analysed in this study, WT maintenance is made exclusively by manufacturers. The maintenance contract assumes the execution of four interventions per year in each turbine, conducted at quarterly intervals. Specifically, the manufacturer performs an electrical preventive maintenance, a mechanical preventive maintenance, a visual inspection and a lubrication operation. The manufacturer is also responsible for any corrective maintenance, whenever necessary, as well as some improvement maintenance that they consider as being fundamental. This service, provided by the manufacturer, is a necessary condition to offer the warranty of the system. The associated maintenance costs to the company are about 38 thousands euros per year per turbine.

In reality, it is not possible to know the exact value for each preventive maintenance and corrective maintenance, since the contract between company that manages the wind farm and the manufacturer is formalized for a 15 years period, and its terms are absolutely confidential.

\subsection{Description of the main States of a wind turbine}

A wind turbine consists of a large set of subsystems and components, some of which are critical to fulfilling the mission of the turbine that consists on producing electricity safely and efficiently. Many of these subsystems or components have multiple failure modes that may (or may not) compromise the efficiency and safety of the wind turbine system.

In this study, it was possible to identify dozens of states for a wind turbine from consulting the manufacturers' manuals. However, this study focuses on data gathered from 21 wind turbines of the same type of advanced technology that are currently installed in a wind farm in Portugal. The data is from the years 2009 and 2010 and was provided by the company that manages and operates the wind farm.

Data were extracted from the SCADA system and each one of record (in the database) contains the identification of the wind turbine, the register of the exact time of occurrence of a particular state and the instantaneous wind speed at the time of this occurrence in each turbine. Table 2 shows the structure of the data along with an example of five successive records.

In the sample of the 21 turbines analysed during 2 years, were detected, on average, 6237 occurrences per turbine, with a standard deviation of 1851 records. They were found only 69 different states registered (from a total of 125 , theoretically possible according to the manual operation of the turbine).
Table 2: Example of the structure of collected data

\begin{tabular}{lcrrrc}
\hline Date & Hour & Min & Sec & State & Wind speed $(\mathrm{m} / \mathrm{s})$ \\
\hline $15-07-2010$ & 21 & 10 & 57 & E9 & 6,2 \\
$15-07-2010$ & 21 & 10 & 58 & E9 & 5,3 \\
$15-07-2010$ & 21 & 28 & 43 & E8 & 3,5 \\
$15-07-2010$ & 21 & 28 & 48 & E1 & 2,3 \\
$15-07-2010$ & 21 & 28 & 52 & E2 & 2,5 \\
\hline
\end{tabular}

They were found only 69 different states registered (from a total of 125 , theoretically possible according to the manual operation of the turbine), each one with a different frequency and time of permanency on the state.

Effectively, many of these 69 states occurred occasionally or with negligible permanency time on state. Note that, if the state represents a failure and the consequent shutdown, the permanency time in that state represents downtime of the machine, which likely leads to loss of energy production. Table 3 presents the listing of the fourteen states that are more frequent and with more time of permanency in state. More details about the main states of wind turbines and related studies can be found in Cajazeira et al. (2012) and Carvalho (2012).

Table 3. List of fourteen states with frequent and permanent occurrences

\begin{tabular}{cl}
\hline State $i\left(E_{i}\right)$ & Designation \\
\hline E1 & Turbine in operation \\
E2 & Lack of wind \\
E3 & Remote control \\
E4 & Mains fault \\
E5 & Maintenance \\
E6 & Cable twisted \\
E7 & Feeding fault \\
E8 & Turbine reset \\
E9 & Fault blade load control \\
E10 & Yaw control error \\
E11 & Pitch control error \\
E12 & Ice detection \\
E13 & Anemometer interface \\
E14 & Generating heating \\
\hline
\end{tabular}

For a better understanding of the operation of the turbine, it is showed thereafter a more detailed description of fourteen states considered more important from the point of view of frequency and permanence in the state, referred in the Table 3.

- State E1 - Turbine in operation: corresponds to a state of normal functioning, in which the turbine operates without technical problems and under suitable environmental factors (e.g. no lack of wind, no storms). The wind conditions are continuously determined and the orientation of both the nacelle and the rotor blades are adjusted in order to optimize the energy produced. All states arising therefrom are 
recorded. The wind turbine is fully operational, although the energy produced depends on wind speed.

- State E2 - Lack of wind: the wind turbine is available, but the wind speed is less than the minimum required to production $(2 \mathrm{~m} / \mathrm{sec})$. When reaching the minimum speed of $2 \mathrm{~m} / \mathrm{sec}$, the turbine automatically restarts.

- State E3 - Remote Control: Each turbine is equipped with a monitoring system remote control, which should be operational 24 hours a day. This equipment allows to obtaining continuously updated information on the machine status, as well as historical data. Being totally independent of wind turbine equipment, the state E3 is not a flaw in the wind turbine, but it means that the machine cannot be accessed remotely. In this situation, the turbine can be deprived of communication with operational control centre, and be yet fully operational.

- State E4 - Mains fault: This state does not represent a flaw in the turbine, but rather a failure of the power grid used. If a predefined number of network failures has been exceeded, the turbine does not restart automatically. Note that, despite this being a very frequent state, it is not a very permanent state of the turbine (E4 status is not included in the most permanent states), thus it is assumed that this last situation rarely arises.

- State E5 - Maintenance: Preventive maintenance actions can be planned and performed at regular intervals; corrective maintenance actions are performed whenever a failure occurs. The wind turbine is unavailable during its permanence in this state.

- State E6 - Cable twisted: power cables and control located in the tower have great freedom of movement, allowing the nacelle to rotate multiple times in the same direction on its axis. During this process, the cables are gradually twisted. After two or three turns of cables, the turbine uses the following period of low wind speed to perform the automatic distortion of cables. If the wind speed is persistently high during a long period and does not permit the previous action, the turbine stops after three complete revolutions and the cables are distorted regardless of wind speed.

- State E7 - Feeding fault: this state represents a failure to convert the power produced by the wind turbine to the proper voltage for the electrical network being used. This occurrence stops the operation of the wind turbine.

- State E8 - Turbine (reset): This condition occurs when, after an attempt for automatic restart (after a state enabling any automatic restart), the turbine cannot do it. Then, a manual reset of the wind turbine is performed, which can be done remotely.

- State E9 - Fault blade load control: the control effort in the turbine is constantly monitored. The state E9 means that an undue effort has been exercised in the blade. The wind turbine is still operating, although with reduced power. The maintenance service has to rectify the effects of stress. The state E9 actively influences the state E11.

- State E10 - Yaw control fault: the direction and wind speed are continuously measured. If the deviation between the direction of the axis of the rotor and wind direction monitored is too large, the position of the nacelle is corrected. The angle that reflects the deviation and the time taken to fix the position of the nacelle is a function of the wind speed. State E10 occurs when the average deviation of the orientation of the rotor relative to the wind direction is greater than a preset angle or the nacelle rotates three times in the same direction about its axis. In this case, the turbine stops (see state E6).

- State E11 - Pitch control error: the turbine has a power control device which aims to adjust the angles of the rotor blades in order to optimize the potency achieved by wind speed and thus ensuring an effective use of the wind energy. The angles of the three blades are continuously monitored. Whenever a difference in the angles of the blades (can be erroneously due to a measurement error) is detected, state E11 arises, which leads to the shutdown of the turbine. The engine restarts automatically. If the problem persists for a predefined number of times, the maintenance service will have to repair the fault. - State E12 - Ice Detection: the accumulation of ice or frost severely reduces the aerodynamic lift of the rotor blades, resulting in a decreased efficiency of the turbine and may even be harmful for people around and for the machine integrity itself. The detection of ice is therefore of utmost importance. Thus, if the temperature is below $2^{\circ} \mathrm{C}$ (presuppose conditions for ice formation), the turbine is automatically turned off.

- State E13 - Anemometer interface: This condition occurs when there is an error in the information gathered by the anemometer (instrument indicator of wind speed). The wind turbine stops.

- State E14 - Generating heating: This state indicates that the protection breaker has tripped due to an overload of electrical current. In these situations, the turbine stops and triggers the realization of a check-up by the maintenance crew.

From the list of the fourteen identified states, the states E9 and E11 are considered frequent and permanent. Analysing the states with longer frequency and permanency than the states E9 and E11, it appears that none of them represents or may represent a failure. Additionally, not all of them imply the stop of the turbine. The graph of Figure 3 gives an idea of the average times among the five more frequent and permanent observed states that effectively represent a failure in the turbine. Furthermore, this system plays a crucial role in optimizing the efficiency of the turbine, as well as a decisive role in the safety of he machine. The description of this system is made in the following section. 


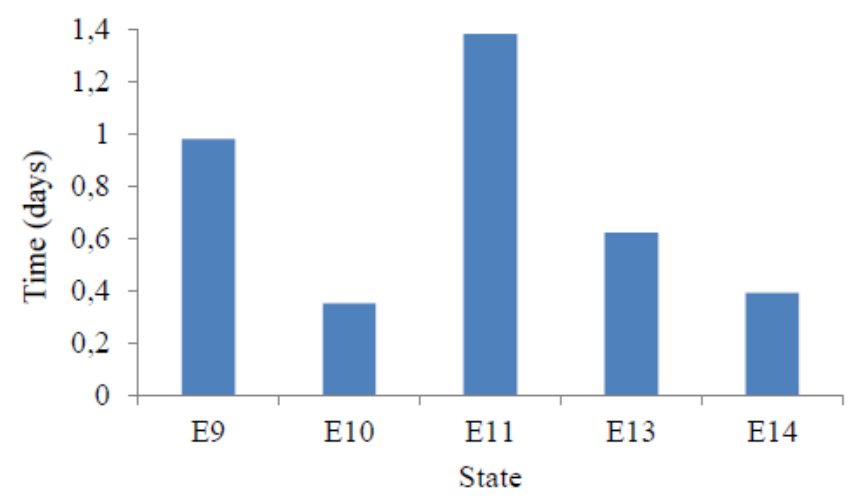

Figure 3. Average time (in days) spent in each of the more permanent five states of failure, per machine in two years

\subsection{Description of a pitch control system}

The purpose of a pitch (power control) system is to prevent that, in the case of high wind speeds, the power of the electric generator be exceeded as well as relieve strain on the structure and components of the wind turbine. The active control (pitch) acts on the aerodynamic forces with the aim of controlling the loads and power.

In the active control, blades may undergo rotation about its longitudinal axis, which makes it changes the angle of attack of the blades with respect to the relative wind speed. This process takes place, most often, through hydraulic systems, which respond to an electronic control which checks the power output. Figure 4 shows a diagram of the different positions of the blade, including the position of flag, stopping the turbine.

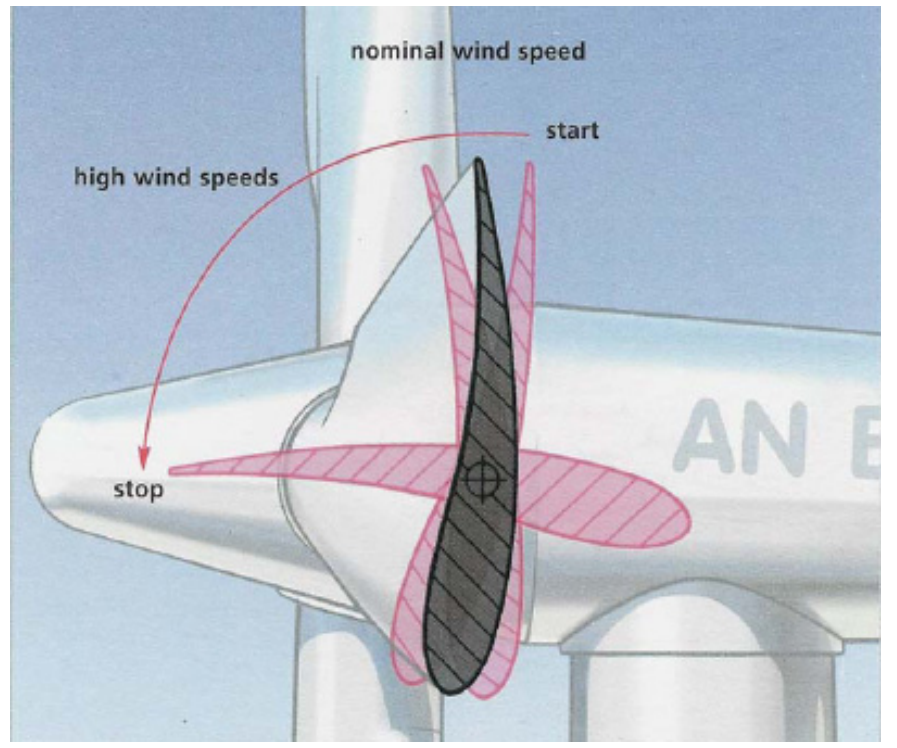

Figure 4. Exemplification of active power control (modified Press Picture AN Windenergie 2010)

In the case of this being too high, the control triggers the mechanism. The main advantages of this system are related to its capability to limit the power for high wind speeds, facilitating the start-up operation, to diminish the efforts and to optimize power when the turbine is operating at partial load.

When the wind speed exceeds the cutting speed, i.e. the maximum speed at which the turbine was designed to operate, or for a maintenance action, blades can be configured so that act as aerodynamic brake, stopping the movement of the rotor. Blades may then be placed in a position flag, to minimize aerodynamic efforts upon them and upon their mechanical components.

This system allows more efficient capture of wind energy, particularly in the speed range between the starting and the nominal speeds, at which the turbine operates at partial load.

\subsection{Failure modes of the pitch control system}

The active power control system assumes primordial importance with regard to safety of the turbine. A flaw in this system, combined with adverse climatic situation (for example, a storm) may lead to an uncontrolled rotation speed of the blades and related catastrophic consequences, including, in the limit, a total destruction of the turbine.

The states which actively influence the reliability of the active control power are the E9 and the E11 states. Figure 5 shows the frequency of these states, by machine, in two years.

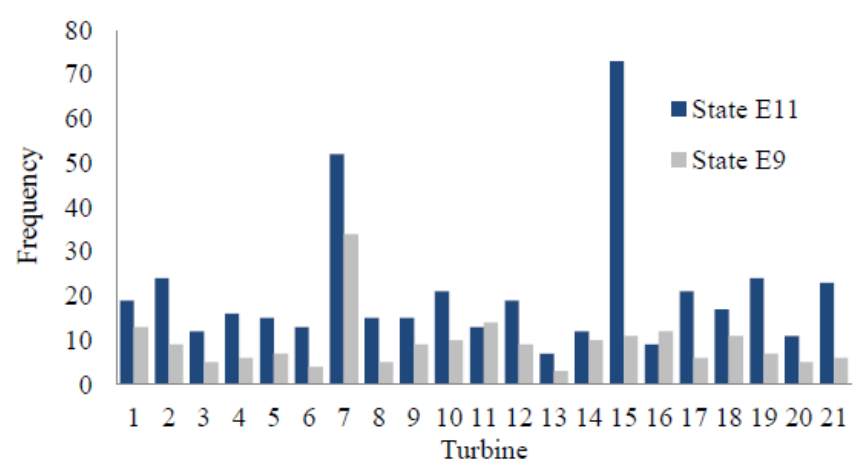

Figure 5. Frequency of the E11 e E9 states, per turbine, during two years

Note that the state E11 leads to a shutdown of the turbine. The state E9, although not leading to a state of absolute unavailability, takes the turbine to an operating state of effort and reduced power, which is undesirable, both by the influence of this state (E11), but also by loss to generate energy inherent in a conditioning operation. 


\section{MAINTENANCE COSTS OF THE PITCH CONTROL DEVICE}

\subsection{Introduction}

Maintenance costs are generally divided into two broad categories: maintenance costs due to the occurrence of failures and maintenance costs due to preventive maintenance. Maintenance costs resulting from a preventive maintenance are the most simple to determine. Maintenance costs determined by the occurrence of faults are more difficult to determine, due to their inherent uncertainty in occurring.

Knowing the costs of maintenance, albeit mere approximations, allows the wind farm company to make better decisions, particularly with regard to contracts for the maintenance established with the manufacturer. However, this information either does not exist or is not public.

In this study it was very difficult to estimate the maintenance costs related to the two main states, E9 and E11. The wind farm company only knows the information that can be observed from the data made available to this study. From that, with relevance to the analysis of maintenance costs, one can highlight the record of the exact time of occurrence of each state in each turbine and the wind speed at the time of occurrence.

Such information allows estimating the cost of downtime, for states E9 and E11, as well as the number of preventive and corrective maintenances carried out in the two years of study. However, the costs of corrective and preventive maintenance, and the number of replacements made, were not revealed by the manufacturer. One can only know approximate values from the experience of experts of this company and of others companies that manage wind farms and who were consulted in context of this work.

Part of the information collected does not follow, therefore, statistical analysis, but rather statements of experts, based on their knowledge and experience and, therefore, they are subject to an increased level of uncertainty.

\subsection{Costs of unavailability}

Tables 4 and 5 summarize the frequency, duration and cost of the resulting unavailability of states E11 and $\mathrm{E} 9$, respectively, per turbine, in the two years.

The cost of downtime shown in the last column of those tables was estimated as a function of wind speed records and the ratio of power with wind speed, displayed in Figure 6.

The data of average wind speed and the respective wasted power by the turbine, and other details, resulting from the appearance of these two states can be found in Qiu, et al. (2012).

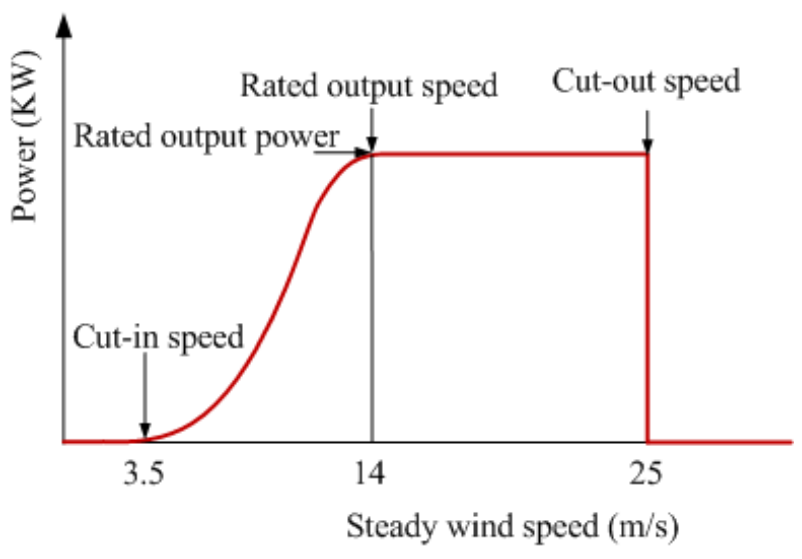

Figure 6. Power curve as a function of wind speed

The energy wasted by the occurrence of each state is given by:

Energy $[\mathrm{MWh}]=($ Power $[\mathrm{KW}] \times \mathrm{MDT}[\mathrm{h}]) / 1000$

where the mean downtime (MDT) is the average time that a system is non-operational for being either in state E9 or state E11.

The cost of downtime was estimated supposing that the energy produced is sold at $90 €$ per MWh.

For state E11, there were 431 failures in the 21 wind turbines in the years 2009 and 2010, which resulted in a total cost of unavailability of $129,733.20 €$ in the same period. Each failure had an average duration of approximately 4 hours and an unavailability cost of $301 €$.

Table 4. Description of state E11 for the 21 machines in the years 2009 and 2010

\begin{tabular}{lccl}
\hline $\begin{array}{l}\text { Turbine } \\
\text { number }\end{array}$ & $\begin{array}{c}\text { Number of } \\
\text { occurrences }\end{array}$ & $\begin{array}{c}\text { Unavailable } \\
\text { time (hh:mm:ss) }\end{array}$ & $\begin{array}{c}\text { Unavailable } \\
\text { cost }(€)\end{array}$ \\
\hline Turbine 1 & 19 & $25: 02: 21$ & 4238.34 \\
Turbine 2 & 24 & $40: 04: 07$ & 3678.24 \\
Turbine 3 & 12 & $102: 29: 58$ & 13004.88 \\
Turbine 4 & 16 & $30: 10: 29$ & 1655.12 \\
Turbine 5 & 15 & $70: 51: 48$ & 7989.76 \\
Turbine 6 & 13 & $150: 01: 48$ & 11954.29 \\
Turbine 7 & 52 & $199: 28: 26$ & 22613.98 \\
Turbine 8 & 15 & $74: 52: 52$ & 9942.31 \\
Turbine 9 & 15 & $22: 10: 43$ & 3310.77 \\
Turbine 10 & 21 & $105: 49: 33$ & 4960.38 \\
Turbine 11 & 13 & $42: 58: 04$ & 5460.92 \\
Turbine 12 & 19 & $64: 43: 34$ & 2426.08 \\
Turbine 13 & 7 & $20: 26: 23$ & 2976.49 \\
Turbine 14 & 12 & $19: 13: 29$ & 1054.58 \\
Turbine 15 & 73 & $169: 52: 10$ & 20512.15 \\
Turbine 16 & 9 & $58: 15: 51$ & 2625.14 \\
Turbine 17 & 21 & $296: 50: 03$ & 1016.93 \\
Turbine 18 & 17 & $15: 56: 08$ & 859.99 \\
Turbine 19 & 24 & $44: 35: 36$ & 2680.60 \\
Turbine 20 & 11 & $19: 31: 45$ & 2272.95 \\
Turbine 21 & 23 & $36: 07: 44$ & 4499.31 \\
\hline TOTAL & 431 & $1609: 32: 52$ & 129733.20 \\
\hline
\end{tabular}


Table 5 also presents the frequency, duration and cost of the resulting unavailability of the state E9 for each turbine in the same years. The same method and (1) were used to determine the unavailable cost of state E9.

Table 5 reveals also that there were 196 failures related to state $\mathrm{E} 9$, which resulted in a total cost of unavailability of $108276.40 €$. This means that each failure had an average duration of approximately 5 hours and a cost of unavailability of $552.40 €$.

Table 5. Description of state E9 for the 21 machines in the years 2009 and 2010

\begin{tabular}{ccll}
\hline $\begin{array}{c}\text { Turbine } \\
\text { number }\end{array}$ & $\begin{array}{c}\text { Number of } \\
\text { occurrences }\end{array}$ & $\begin{array}{c}\text { Unavailable } \\
\text { time (hh:mm:ss) }\end{array}$ & $\begin{array}{c}\text { Unavailable } \\
\text { cost }(€)\end{array}$ \\
\hline Turbine 1 & 13 & $45: 51: 39$ & 7937.35 \\
Turbine 2 & 9 & $3: 38: 29$ & 430.03 \\
Turbine 3 & 5 & $29: 50: 09$ & 2062.18 \\
Turbine 4 & 6 & $40: 39: 45$ & 3317.17 \\
Turbine 5 & 7 & $23: 54: 58$ & 4116.96 \\
Turbine 6 & 4 & $101: 33: 18$ & 14475.69 \\
Turbine 7 & 34 & $147: 31: 25$ & 22322.40 \\
Turbine 8 & 5 & $26: 24: 51$ & 3609.12 \\
Turbine 9 & 9 & $42: 55: 49$ & 4626.94 \\
Turbine 10 & 10 & $26: 51: 57$ & 4945.14 \\
Turbine 11 & 14 & $39: 08: 07$ & 6794.74 \\
Turbine 12 & 9 & $145: 50: 09$ & 3260.08 \\
Turbine 13 & 3 & $64: 27: 26$ & 5319.53 \\
Turbine 14 & 10 & $12: 17: 27$ & 2006.23 \\
Turbine 15 & 11 & $94: 17: 37$ & 7117.12 \\
Turbine 16 & 12 & $36: 51: 07$ & 4005.19 \\
Turbine 17 & 6 & $8: 58: 39$ & 1656.35 \\
Turbine 18 & 11 & $7: 10: 01$ & 1317.56 \\
Turbine 19 & 7 & $20: 54: 40$ & 3858.10 \\
Turbine 20 & 5 & $8: 43: 11$ & 1204.83 \\
Turbine 21 & 6 & $22: 04: 24$ & 3893.69 \\
\hline TOTAL & 196 & $949: 55: 08$ & 108276.40 \\
\hline
\end{tabular}

\subsection{Preventive maintenance costs}

For the preventive maintenance of the active power control system, experts mentioned the following:

- Manpower: approximately $480 €(60 € / \mathrm{h}-\mathrm{man}$, always considering 2 men and 4 hours);

- Lubricants: 100€;

- Parts: variable (can take, or not, anything);

- Displacement: variable (it can be done additionally with other works).

According to this information, it can be said that a preventive maintenance of the active power control system costs, at least, $580 €$, and that the time for its realization rounds 4 hours (which represents an approximate unavailability cost of $293 €$ due to preventive maintenance, assuming an average wind speed of $8 \mathrm{~m} / \mathrm{sec}$ ).

\subsection{Corrective maintenance costs}

For corrective maintenance of the power control active system, experts report that when the maintenance team is called to intervene in the event of an error in this system (state E11), the maintenance usually consists in replacing the engine of the blade in which the error was detected. To ensure machine availability, repairs are never made on site. The motor is replaced and thereafter is repaired in the factory. The experts indicate that the cost of each engine is around $2,000 €$.

When the maintenance team makes an intervention in the failure load control (E9), usually they replace the sensors that somehow quantify the load exerted on the blade. A new sensor is around $50 €$.

Note that the repair is not carried out whenever one of the states, E9 or E11, is detected. The wind turbine has reaction mechanisms for these failures. The error manifested by the state E11, despite being a mandatory stopping error, it deploys an automatic restart of the system. In the case of this restart fails for three consecutive times, the maintenance team is called in order to fix it. The error E9 is not a mandatory stopping error, but it implies a loss of power and requires human intervention to resume with normal power (state E8), which does not mean that there is always maintenance work. This only occurs when the state E8 cannot put the machine in normal operation.

By analysing data from the 21 wind turbines in the years 2009 and 2010, from 431 recorded instances of state E11, it resulted in 53 repairs (replacements), i.e. $12.3 \%$ of cases requiring maintenance. Among the 196 occurrences of state E9, 44 triggered a corrective maintenance, which corresponds to $22.4 \%$ of cases.

All instances of states E11 and E9 (in 2009 and 2010) were immediately detected and recorded in the control system of each turbine. Moreover, the probability of not detecting a malfunction in the control system of active power was negligible, since it would be necessary to have a communication failure (state E3), and simultaneously a failure in the pitch system (denoted by state E11). Thus, nondetection costs were not considered. In the unlikely event of an occurrence of this kind, the consequences are unpredictable.

\subsection{Replacement costs}

Technicians refer that a replacement of the entire active power control system of a blade will cost approximately $10,000 €$. So, the replacement of the system of three blades will be around $30,000 €$. 


\subsection{Total maintenance costs}

The annual total maintenance cost of the active power control system can be given by (2).

$$
\begin{aligned}
& C=C_{C M_{-} E 11} \times\left(n .^{\circ} \text { of } C M_{-} E 11\right)+ \\
& +C_{C M_{-} E 9} \times\left(n .^{\circ} \text { of } C M_{-} E 9\right)+ \\
& +4 \times\left(C_{P M}+C_{U_{-} P M}\right)+C_{U_{-} E 11}+C_{U_{-} E 9}
\end{aligned}
$$

where:

$C$ : total cost of maintenance of the active power control system of the 21 machines in the years 2009 and 2010

$C M$ E11: corrective maintenance of state E1 1

$C M_{-}$E9: corrective maintenance of state E9

$C_{P M}$ : preventive maintenance cost of pitch system

$C_{C M E E 11}$ : corrective maintenance cost of state E11

$C_{C M_{-} E 9}$ : corrective maintenance cost of state E9

$C_{U M P}$ : unavailability cost, due to preventive maintenance

$C_{U_{-} E 11}$ : unavailability cost, due to state E11

$C_{U_{-} E 9}$ : unavailability cost, due to state E9

According to the information obtained about the costs, it was estimated, by (2), that the amount spent on maintenance of the active power control system of 21 wind turbines of the wind farm was approximately $49,2873 €$ during the two years under review. Thus, on average, the annual maintenance cost of each active power control system was around $11,735 €$.

Note that the only available information for the maintenance cost is that which prevails at the contract between the company and the manufacturer, i.e. $38,000 €$ per year per turbine. It is estimated, therefore, that $11,735 €$ is specifically related to the maintenance of the active power control system.

\section{CONCLUSIONS}

The main objective of this paper was to provide an estimate for the maintenance costs of an active power control system of a wind turbine.

It was analysed the information given by the company that manage the wind farm, which basically consists on the register of the exact time of occurrence of a particular state and the wind speed at the time of this occurrence in each turbine. By a detailed analysis of two years of operation of 21 identical wind turbines, it was found that there are two dependent states of wind turbine that are of particular interest, since they are states of a subsystem of the wind turbine, the active power control, that:

i. It reveals frequent failures and large residence time compared to other systems of the wind turbine;

ii. it is crucial in the optimization of the turbine efficiency; and iii. it is very important with regard to the safety of the turbine.

The unavailability costs were determined, knowing the duration of the stops (or not fully operational), the average wind speed during this stops, thus deducting the costs for the loss in the production of energy.

The number of preventive and corrective maintenances carried out in the two years of study was also counted from the data collected. However, corrective and preventive maintenances and replacements costs are not disclosed by the manufacturer. It is only known approximate values from the expert's experience, from this and others companies that manage wind farms and who were inquired by the work team of the present study. Therefore, part of the information collected does not follow statistical analysis, but rather statements of experts, based on their knowledge and experience and, consequently, they are subject to uncertainty.

Planning the maintenance of complex systems, as the active power control system, is commonly associated with large amounts of data that are quickly processed and almost exists total dependence on historical references and on the quality and experience of experts and maintenance engineers. In this context, maintenance planning is often a very difficult process. Sometimes, unrealistic decisions come out from the process. It is expected that Fuzzy Set Theory, applied in the planning process of maintenance systems, will then lead to more realistic results. For example, in Carvalho (2012), the uncertainty provided by the expert's opinions was modelled by this theory, which is an appropriate tool to deal with these uncertainty cases.

Until now, and as far as you know, maintenance costs of a wind turbine have not been released (by manufactures). This work presented an estimate for this cost. In this way, this work constitutes a starting point for others studies on maintenance of wind turbines that need a rough estimation of such costs..

\section{ACKNOWLEDGEMENTS}

This work was financed with FEDER Funds by Programa Operacional Fatores de Competitividade COMPETE and by National Funds by FCT Fundação para a Ciência e Tecnologia, Project: FCOMP-01-0124-FEDER-022674.

\section{REFERENCES}

Bertling L., Ackermann T., Nilsson J., Ribrant J. (2006). Pre-study on reliability-centered maintenance for wind power systems with focus on condition monitoring systems, Elforsk report 06:39, May 2006. 
Cajazeira, C., Nunes, E., Telhada, J. \& Carvalho, M. (2012). RAM factors in the operation and maintenance phase of wind turbines. Proc. of The International Conference on Industrial Engineering and Operations Management (ICIEOM). Guimarães, Portugal, 2012, ID315.1-ID315.10.

Carvalho, M. (2012). Análise e Avaliação de Períodos de Inspeção em Sistemas de Natureza Tecnológica. PhD Thesis Dissertation, Dept. Industrial and Systems Engineering, University of Minho.

Carvalho, M., Nunes, E, \& Telhada, J. (2013). Maintenance Costs of a Pitch Control Device of a Wind Turbine. Proceedings of the World Congress on Engineering 2013, July 3 - 5, London, U.K. 569-574.

Catalog of AN Windenergie, (2010). BonusGermany.

Garg, A. \& Deshmukh, S.G. (2006). Maintenance management: literature review and directions. Journal of Quality in Maintenance Engineering. 12(3), 205-238.

INEGI - Parques Eólicos em Portugal - Dezembro de 2010. Available:

http://www.inegi.up.pt/publicacoes/outras/Parque s Eolicos Dez10 rev.pdf.

Julia, N. \& Lina, B. (2007). Maintenance management of wind power systems using condition monitoring systems life cycle cost analysis for two case studies. IEEE Transactions on Energy Conversion, vol. 22(1), 223(7).

Kumar, D. \& Pandey, P. C. (1993). Maintenance planning and resource allocation in urea fertilizer plant. Quality and reliability Engineering International Journal, vol. 9, 411-423.

Manwell J.F., McGowan J.G., Rogers A.L. (2002) Wind Energy Explained - Theory, Design and Application, John Wiley \& Sons, Inc.

Morthorst P. E. (2003). Wind Energy - The Facts Costs \& Prices, Risø National Laboratory, Denmark. Volume 2, 94-110.

Naranjo, E., Sumper, A., Bellmunt, O., Ferre, A. \& Rojas, M. (2011). Pitch control system design to improve frequency response capability of fixedspeed wind turbine systems. European Transactions on Electrical Power, vol. 21, 1984-2006.

Pham, H. \& Wang, H. (1996). Imperfect maintenance. European Journal of Operational Research. 94, 425-438.

Qiu, Y., Feng, Y., Tavner, P., Richardson, P., Erdos, G. \& Chen, B. (2012). Wind turbine SCADA alarm analysis for improving reliability. Wind Energy. vol. 15, 951-966.

Siemens AG. (2007). Nacelle of a Wind Turbine. Retrieved October, 22, 2013, from http://www.powergeneration.siemens.com/press/ press-pictures/windpower/nacelle-of-awindturbine-2-3.htm.
Teresa, H. (2007). Wind turbines: designing with maintenance in mind; unscheduled maintenance costs can weaken a company's bottom line, so wind turbine manufacturers are beginning to design with maintenance in mind. Power Engineering, vol.111, no.5, 36(3).

Walford C. A. (2006). Wind Turbine Reliability: Understanding and Minimizing Wind Turbine Operation and Maintenance Costs. Sandia Report, Sandia National Laboratories. 